\title{
High-dose-rate brachytherapy of primary cutaneous B-cell lymphoma: the first reported case series
}

\author{
Artur J. Chyrek, MD', Grzegorz M. Bielęda, MSc'2, wojciech M. Burchardt, MD, PhD', Adam Chicheł, MD, PhD' \\ IBrachytherapy Department, Greater Poland Cancer Centre, Poznań, Poland, Electroradiology Department, University of Medical Sciences, \\ Poznań, Poland, ${ }^{3}$ Medical Physics Department, Greater Poland Cancer Centre, Poznań, Poland
}

\begin{abstract}
Purpose: Cutaneous B-cell lymphomas (CBCLs) are a rare group of diseases. External beam radiation therapy is recommended to treat CBCLs in all subtypes for locally advanced cases. However, there are no reports on high-doserate brachytherapy (HDR-BT) exclusively dedicated to CBCLs. The purpose of this paper was to report the first case series of CBCLs treated with HDR-BT.

Material and methods: Seven patients were treated between 2011 and 2019, with 12 skin lesions histopathologically proven as CBCLs. There were four T1a and eight T2a lesions. HDR-BT was prescribed as the first-line treatment for all cases, as the second-line treatment for recurrences after surgical failure for 4 patients, and as an adjuvant treatment for 1 case. The median total dose was 36 Gy (range, 30-40 Gy) in 10 fractions (range, 6-10 fractions), with a median overall treatment time of 11 days (range, 4-11 days). Treatment toxicity was assessed accordingly to the RTOG scale.

Results: The mean follow-up was 41 months. Local control was $100 \%$. The rates of early toxicity were as follows: erythema (G1) - 33\%, patchy epidermal desquamation (G2) - 25\%, confluent epidermal desquamation (G3) - 25\%, and minor bleeding (G4) - 17\%. The reported rates of late toxicity included slight depigmentation (G1) - 59\%, small telangiectasia (G2) - 8\%, massive telangiectasia (G3) - 25\%, and small ulceration (G4) in one site irradiated interstitially (8\%).

Conclusions: HDR-BT allows for achieving high local control of CBCLs with relatively low-late toxicity in the form of skin discoloration in most patients.

J Contemp Brachytherapy 2020; 12, 3: 24l-247 DOI: https://doi.org/10.5114/jcb.2020.96864
\end{abstract}

Key words: B-cell lymphomas, skin, HDR, brachytherapy.

\section{Purpose}

Primary cutaneous lymphomas (PCLs) are a very heterogeneous and relatively rare group of diseases, with an estimated annual incidence of $0.7 / 100,000$ citizens [1]. They differ from other lymphomas, as they occur only in the skin without invading other organs and tissues. PCLs are divided into two main subgroups: cutaneous T-cell lymphomas (CTCLs) and cutaneous B-cell lymphomas (CBCLs). The latter is less common and represents less than $25 \%$ of all PCLs. CBCLs contain primary cutaneous follicle center lymphomas (PCFCLs), primary cutaneous marginal zone B-cell lymphomas (PCMZLs) about the indolent course, primary cutaneous diffuse large B-cell lymphomas, leg type (PCLBCLs LT), and primary cutaneous diffuse large B-cell lymphoma, other types (PCLBCLs OT) whose course is usually more aggressive $[2,3]$.

According to the most important recommendations for CBCLs treatment, in all their subtypes and locally advanced cases, a treatment with ionizing radiation with external beam radiation therapy (EBRT) methods is recommended $[4,5,6,7]$. Even though high-dose-rate brachytherapy (HDR-BT) is a radiation technique enabling delivery of higher doses more precisely than EBRT [8], and results in excellent treatment outcomes for other skin cancer types $[9,10]$, none of those above-mentioned recommendations indicate BT as a treatment option for CBCLs. It is probably due to only a few reports in literature, which directly correspond to PCLs treatment using HDR-BT in palliative setting and for lesions derived from T-cell lines [11,12]. However, there are no reports on HDR-BT exclusively dedicated to CBCLs. The purpose of this paper was to report the first case series of CBCLs treated with HDR$\mathrm{BT}$, and to initiate filling the gap in the literature.

\section{Material and methods}

There were 7 patients treated between 2011 and 2019 (6 males and 1 female), with 12 skin lesions histopathologically proven as CBCLs (5 cases of PCMZL, 4 cases of PCLBCL OT, 2 cases of PCFCL, 1 case of PCLBCL LT). All patients were referred for BT treatment after a com- 
plete assessment performed by a hematologist. The mean age at the time of presentation was 53.3 years (median, 55.4; range, 34.4-72.2). Staging was assessed according to TNM classification, determined by the International Society for Cutaneous Lymphomas and the Cutaneous Lymphoma Task Force of the European Organization of Research and Treatment of Cancer (Table 1) [13], and included T1a and T2a in 4 and 8 of treated lesions, respectively. However, the clinical manifestation of some lesions did not correlate thoroughly with TNM classification: in 4 cases, multi-nodular changes were described (clear T2a), in 4 cases - solitary nodules (clear T1a), but four tumors (two in two patients), which co-occurred in the skin area of a diameter less than $15 \mathrm{~cm}$ (T2a) were treated as solitary tumors, as they were located in different anatomical sites (cheek and forehead; left and right lumbar area).

HDR-BT was prescribed as the first-line treatment for all studied cases, as the second-line treatment for recurrences after surgical failure for 4 cases, and as an adjuvant treatment after insufficient surgery for 1 patient. Additionally, it is to be noted that 5 out of the tumors mentioned above were treated as new consecutive lesions that appeared in time in 2 patients, who were treated earlier in our institute. Moreover, three quarters of treated lesions were staged as secondary according to the TNM classification (feature $\mathrm{rT}$, recurrent tumor).

According to TNM location indicators, the lesions were located as follows: head and neck (HN) 59\%, lower back and buttock (LBB) 25\%, upper back (UB) $8 \%$, and left lower arm and hand (LLAH) 8\% (Figure 1) [13].

All tumors were treated with MicroSelectron HDR afterloader (Nucletron, an ELEKTA company, Stockholm, Sweden) using ${ }^{192}$ Ir stepping source, with nominal activity $10 \mathrm{Ci}$. Out of 12 lesions, one was treated interstitially (6 single-leader applicators) due to the thickness of infiltration well above $5 \mathrm{~mm}$ and was planned three-dimen- sionally. The remaining eleven tumors were treated superficially with Freiburg-flap applicators and planned in 3D (3 lesions) or in 2D setting (8 lesions). As for 3D planning, patients' anatomies and application reconstructions as well as dose-volume calculations were completed with Oncentra Brachy software (Nucletron, an ELEKTA company, Stockholm, Sweden).

In cases of two-dimensional planning, precise measurements of tumors and patients' skin marking were performed by a dedicated physician. The Freiburg-flap applicator size was adjusted to cover the tumor with a $5 \mathrm{~mm}$ margin in all directions. 2D treatment plans were prepared without imaging. In the phantom, a physicist created parallel catheters using the same amount as the number of channels in a real applicator, separated by $1 \mathrm{~cm}$. Source positions located above the lesion plus margins were activated. A standard step size of the source was set at $5 \mathrm{~mm}$. Subsequently, parallel axis dose points were made for each active source position at a distance of $10 \mathrm{~mm}$. Dose distribution was normalized to these points and then, a plan was optimized using dose point optimization with a distance option and dwell-time gradient ratio (DTGR) of 0.3 . In such a plan, $100 \%$ isodose was located $5 \mathrm{~mm}$ beneath the skin surface and intersects the patient's skin at a distance of 3 to $5 \mathrm{~mm}$ from the applicator (Figure 2).

In cases of three-dimensional planning for superficial applications, after the applicator was placed and secured on a tumor and the skin was marked appropriately, computed tomography (CT) with a $3 \mathrm{~mm}$ slice thickness was performed. Next, dedicated physician delineated clinical target volume (CTV) and organs at risk (OARs), and the physicist reconstructed the applicator digitally. The source positions above the CTV were activated to plan an optimal dose distribution. There was no margin added to CTV. Then, axis dose points were combined and adapted to the thickness of the lesion, or the applicator points were added manually and adapted to deeper surface of

Table 1. ISCL/EORTC proposal on TNM classification of cutaneous lymphoma other than mycosis fungoides and Sézary syndrome [13]

\begin{tabular}{|c|c|c|c|}
\hline Stage & $T$ & $\mathrm{~N}$ & $M$ \\
\hline 0 & - & $\begin{array}{l}\text { No clinical or pathologic lymph node } \\
\text { involvement }\end{array}$ & $\begin{array}{l}\text { No evidence of extracutaneous non- } \\
\text { lymph node disease }\end{array}$ \\
\hline 1 & $\begin{array}{l}\text { Solitary skin involvement } \\
\text { A: A solitary lesion }<5 \mathrm{~cm} \text { in diameter } \\
\text { B: A solitary lesion }>5 \mathrm{~cm} \text { in diameter }\end{array}$ & $\begin{array}{l}\text { Involvement of } 1 \text { peripheral lymph } \\
\text { node region that drains an area of } \\
\text { current or prior skin involvement }\end{array}$ & $\begin{array}{l}\text { Extracutaneous non-lymph node dis- } \\
\text { ease present }\end{array}$ \\
\hline 2 & $\begin{array}{l}\text { Regional skin involvement: multiple } \\
\text { lesions limited to } 1 \text { body region or } \\
2 \text { contiguous body regions } \\
\text { A: All-disease-encompassing in a }<15 \mathrm{~cm} \\
\text { in diameter circular area } \\
\text { B: All-disease-encompassing in a }>15 \text { and } \\
<30 \mathrm{~cm} \text { in diameter in circular area }\end{array}$ & $\begin{array}{l}\text { Involvement of } 2 \text { or more peripheral } \\
\text { lymph node regions or involvement } \\
\text { of any lymph node region that does } \\
\text { not drain an area of current or prior } \\
\text { skin involvement }\end{array}$ & - \\
\hline 3 & $\begin{array}{l}\text { Generalized skin involvement } \\
\text { A: Multiple lesions involving } 2 \text { noncontig- } \\
\text { uous body regions } \\
\text { B: Multiple lesions involving } \geq 3 \text { body re- } \\
\text { gions }\end{array}$ & Involvement of central lymph nodes & - \\
\hline
\end{tabular}

ISCL - International Society for Cutaneous Lymphomas, EORTC - European Organization of Research and Treatment of Cancer 


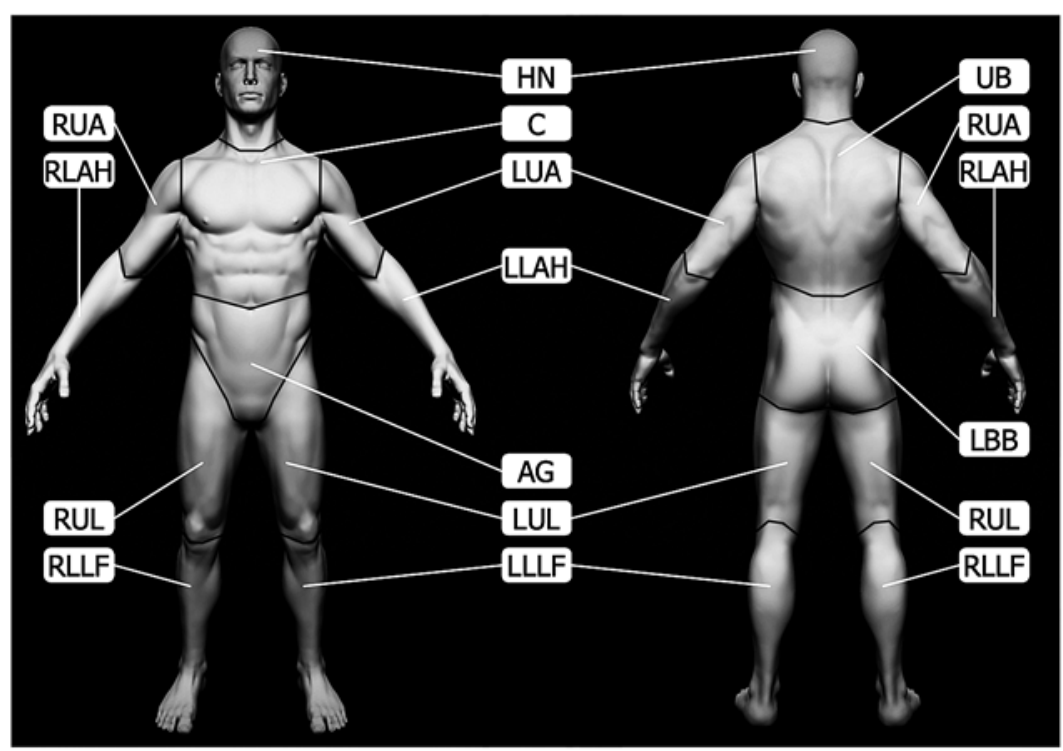

\begin{tabular}{|c|l|}
\hline HN & Head \& Neck \\
\hline C & Chest \\
\hline LUA & Left Upper Arm \\
\hline LLAH & Left Lower Arm \& Hand \\
\hline AG & Abdominal \& Genital \\
\hline LUL & Left Upper Leg \\
\hline LLLF & Left Lower Leg \& Feet \\
\hline RUA & Right Upper Arm \\
\hline RLAH & Right Lower Arm \& Hand \\
\hline RUL & Right Upper Leg \\
\hline RLLF & Right Lower Leg \& Feet \\
\hline UB & Upper Back \\
\hline LBB & Lower Back \& Buttock \\
\hline
\end{tabular}

Fig. 1. Visual representation of skin surface regions of a human body according to the TNM classification [13] (the figure is based on the anatomical model by Stefan Polster, available at https://www.artstation.com/artwork/X28Yl)

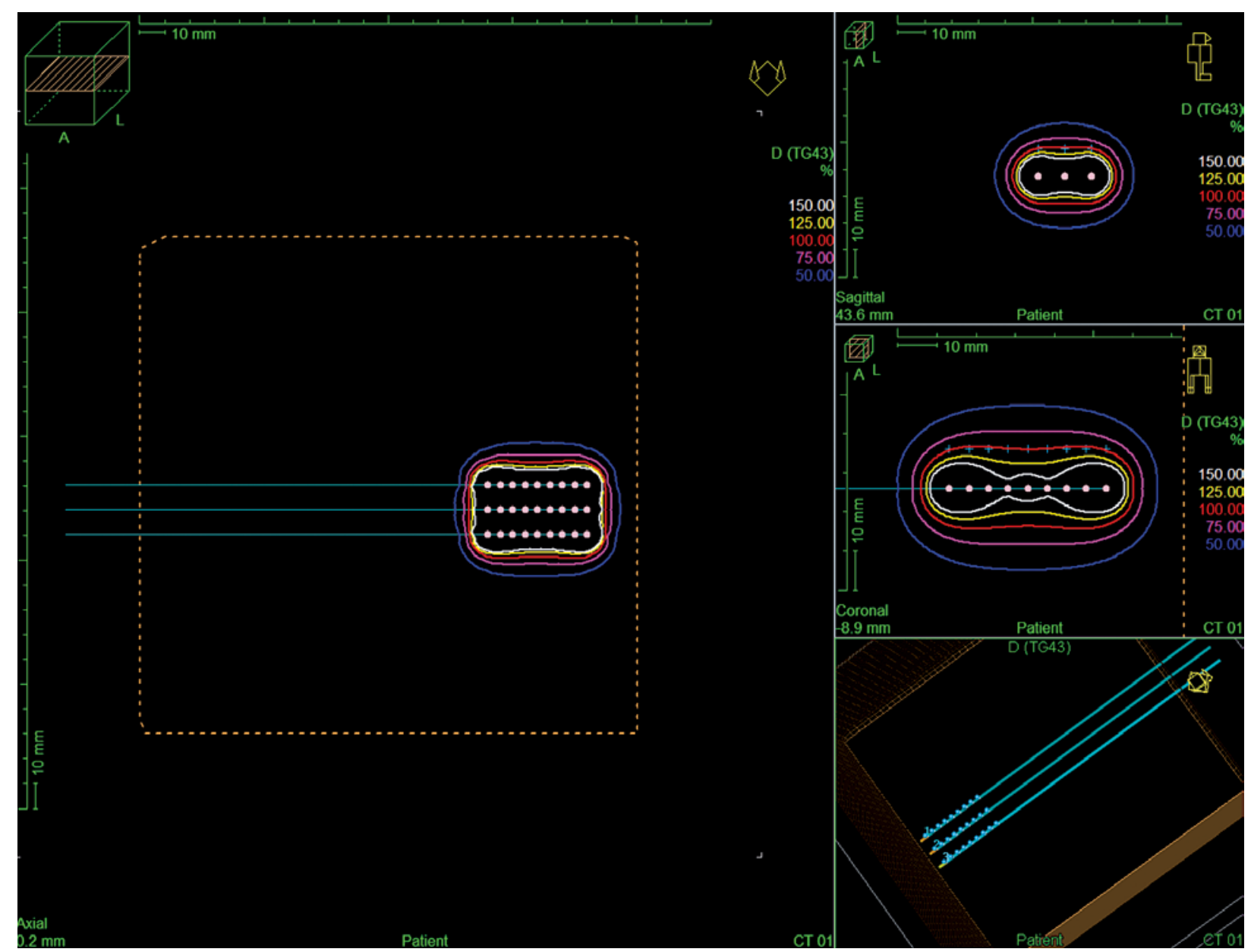

Fig. 2. Reconstruction of $2 \mathrm{D}$ planned application in a TPS phantom. Optimization dose points located at $10 \mathrm{~mm}$ from the active dwell positions in the plane parallel to the applicator 


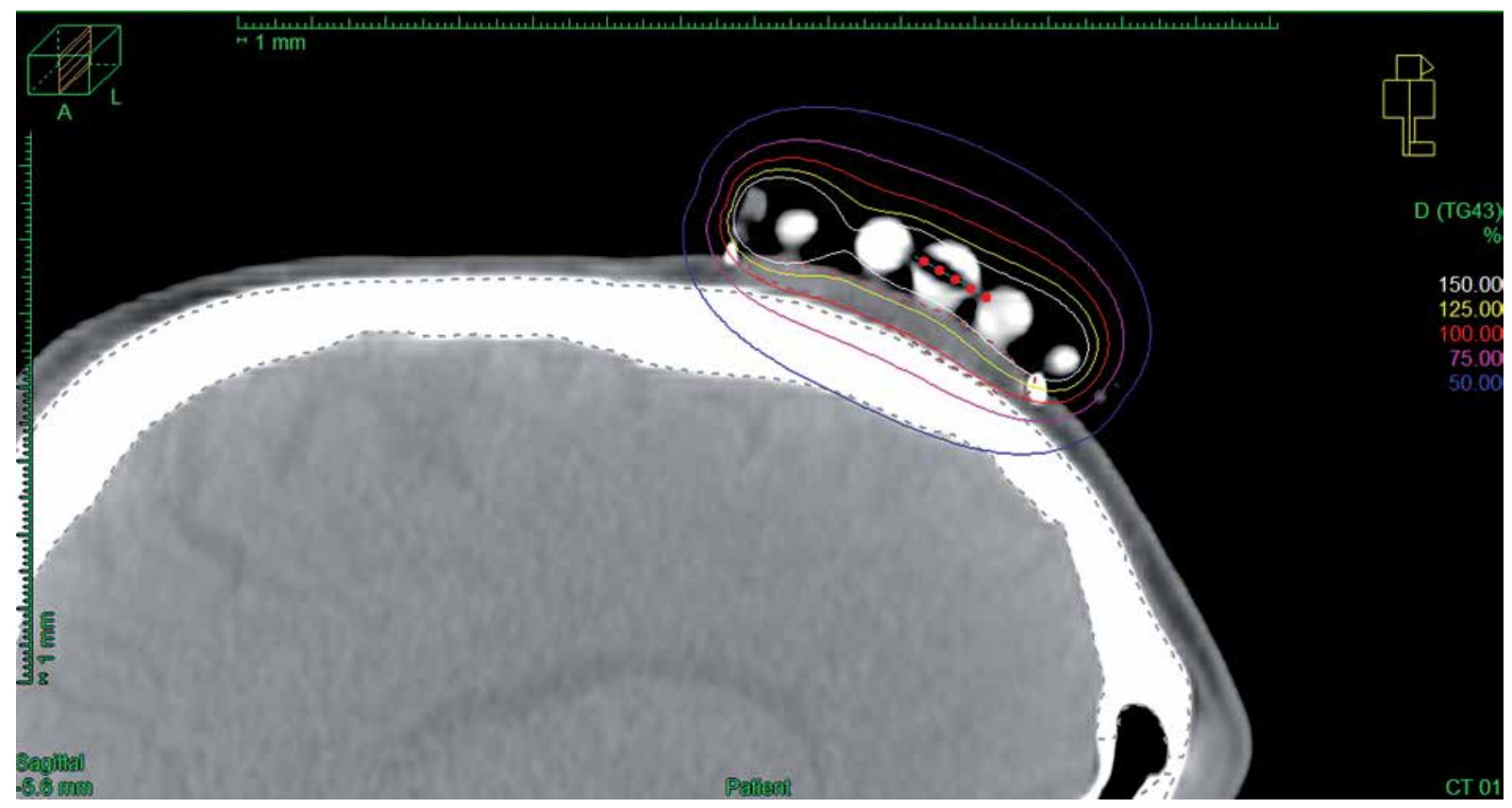

Fig. 3. Sagittal CT reconstruction of 3D planned contact application for tumor localized on the scalp of the patient. 100\% isodose is shaped to cover the target and avoid the skull

the lesion. Dose distribution was normalized to the defined points and then optimized using dose point optimization with a distance option. Additionally, the dose distribution with graphical optimization was adjusted for every patient (Figure 3).

In a single case of interstitial application, $\mathrm{CT}$ imaging was done with a slice thickness of $2 \mathrm{~mm}$. Once the CTV and OARs were delineated, interstitial applicators were digitally reconstructed. No markers were used to avoid artifacts, as the air in the applicators' lumen contrasted sufficiently well with surrounding tissues. The step size of the source was set at $2.5 \mathrm{~mm}$. Dose distribution was optimized with inverse planning simulated annealing (IPSA), and source positions were activated inside the CTV. Again, DTGR of 0.3 was used. The final dose distribution was manually adjusted with graphical optimization (Figure 4).

Median planned physical dose (PD) was 36 Gy (range, 30-40 Gy) in 10 fractions (range, 6-10 fractions), with median overall treatment time (OTT) of 11 days (range,

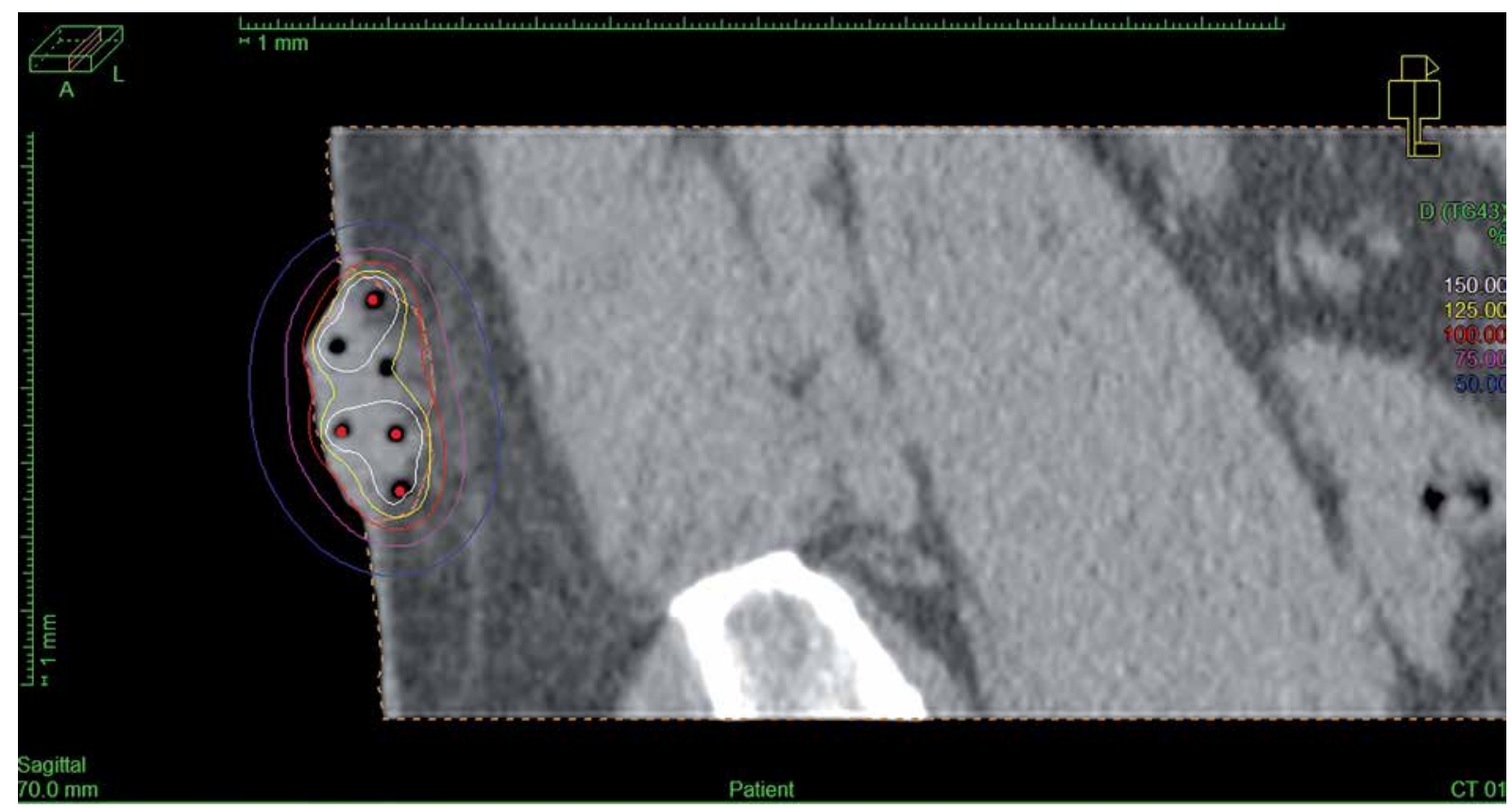

Fig. 4. Sagittal CT reconstruction of interstitial application with 6 catheters. The treated region is clearly visible in CT images. Dose distribution was optimized graphically to cover the target 
4-11 days). The most frequent fractionation pattern was ten times 3.6 Gy (OTT, 11 days), which was used to treat seven lesions. The used regimens differed due to three factors, including the lack of recommended doses for HDR-BT modality, patients' convenience, and their possibility to commute for the treatment.

To compare different fractionation patterns, PDs were calculated to biologically effective doses (BED) and the equivalent total dose in 2 Gy per fraction $\left(\mathrm{EQD}_{2}\right)$ both for CBCLs' cells and early toxicity $(\alpha / \beta=10 \mathrm{~Gy})$ and for late effects $(\alpha / \beta=3$ Gy) $[14,15]$. The equation used for calculations was as follows:

$\mathrm{BED}=\mathrm{nd}[1+\mathrm{d} /(\alpha / \beta)]$ and $\mathrm{EQD}_{2}=\mathrm{BED} /[1+2(\alpha / \beta)]$,

where $\mathrm{n}$ - number of fractions, $\mathrm{d}$ - fraction dose, $\alpha / \beta-$ the ratio of coefficients determining the death of cells due to the passage of one or more radiation quanta.

The cancerous cells' repopulation factor was not included in the calculations because of short OTTs (<14 days).

The first control visit was scheduled four weeks after BT completion, and subsequent assessments were at intervals of 2 to 6 months. Treatment toxicity was evaluated according to the RTOG scale [16]. Early radiation reactions were assessed at the first control visit, late effects were noted after three months and till the end of follow-up. Full patient characteristics, detailed lesions' and treatment data are presented in Table 2. No statistical analyses were performed due to small patients and tumors numbers.

\section{Results}

The mean follow-up for all patients resulted in 41 months (median, 40.2; range, 6-101.2 months). Mean BED for tumor and early reactions was $50.3 \mathrm{~Gy}$ (median, 49; range, 39-57.6 Gy), and mean $\mathrm{EQD}_{2}$ for tumor and early reactions was $41.9 \mathrm{~Gy}$ (median, 40.8; range, 32.5-48 Gy). With the doses delivered, both the complete remission (CR) rate and local control (LC) rate for all the tumors at the last follow-up visit was $100 \%$. However, the treatment was associated with early skin reactions in all cases. The rates of early reactions at the first control visit were as follows: erythema (G1) 33\%, patchy epidermal desquamation (G2) 25\%, confluent epidermal desquamation (G3) $25 \%$, and minor bleeding (G4) $17 \%$. Despite the already mentioned fact of recurrences in two patients after the first course of HDR-BT (patients no. 2 and 3), at the last follow-up visit, none of the patients presented signs of active disease.

Mean doses calculated for late reactions included BED - 84 Gy (median, 79.2; range, 60-108 Gy) and EQD - 50.4 Gy (median, 47.5; range, 36-64.8 Gy). Skin late effects appeared in the irradiated areas in all cases. Most of them were slight depigmentation, G1 (59\%). In one case, there was a small telangiectasia, G2 (8\%). However, in one patient (patient no. 3), who was treated for four separate lesions, an increased radiation reaction was observed in all treated sites; in three sites irradiated superficially, massive telangiectasia developed, G3 (25\%), in one site irradiated interstitially, small ulceration developed in time, G4 $(8 \%)$.

Results, toxicity, and calculated doses for lesions are presented in Table 3.

\section{Discussion}

Recommendations for treatment methods for solitary or localized CBCLs vary depending on their histopatho-

Table 2. Patients, lesions, and treatment characteristics

\begin{tabular}{|c|c|c|c|c|c|c|c|c|c|c|c|c|}
\hline $\begin{array}{l}\text { Patient } \\
\text { ID }\end{array}$ & Sex & $\begin{array}{l}\text { Age at } \\
\text { diagnosis } \\
\text { (years) }\end{array}$ & Pathology & $\begin{array}{l}\text { Lesion } \\
\text { ID }\end{array}$ & $\begin{array}{l}\text { Start } \\
\text { of BT }\end{array}$ & $\begin{array}{l}\text { Indication } \\
\text { for BT }\end{array}$ & TNM & Localization & BT method & PD & Fx no. & OTT \\
\hline 1 & $M$ & 55.4 & PCLBCL LT & 1 & $\operatorname{Jan} 2013$ & $P$ & cT1aNOMO & $\mathrm{HN}$ & Contact 2D & 36 & 10 & 9 \\
\hline \multirow[t]{3}{*}{2} & M & 58.7 & PCMZL & 2 & Dec 2012 & $R$ & rT2aNOMO & $\mathrm{HN}$ & Contact 2D & 36 & 10 & 11 \\
\hline & & & & 3 & Sep 2014 & $P$ & rT2aNOMO* & $\mathrm{HN}$ & Contact 2D & 36 & 10 & 11 \\
\hline & & & & 4 & Sep 2014 & $P$ & rT2aNOMO* & $\mathrm{HN}$ & Contact 2D & 36 & 10 & 11 \\
\hline \multirow[t]{4}{*}{3} & M & 42.1 & PCLBCL OT & 5 & Sep 2011 & $R$ & rT2aNOMO & UB & Contact 2D & 40 & 10 & 11 \\
\hline & & & & 6 & May 2014 & $P$ & rT1aNOMO & LBB & Interstitial 3D & 36 & 6 & 4 \\
\hline & & & & 7 & May 2015 & $P$ & rT2aNOMO* & LBB & Contact 3D & 36 & 10 & 11 \\
\hline & & & & 8 & May 2015 & $P$ & rT2aNOMO* & LBB & Contact 3D & 36 & 10 & 11 \\
\hline 4 & $\mathrm{~F}$ & 77.2 & PCMZL & 9 & May 2013 & $R$ & rT2aNOMO & LLAH & Contact 2D & 36 & 9 & 11 \\
\hline 5 & $M$ & 66.8 & PCFCL & 10 & Feb 2014 & $R$ & rT2aNOMO & $\mathrm{HN}$ & Contact 2D & 36 & 6 & 4 \\
\hline 6 & M & 34.4 & PCMZL & 11 & Oct 2014 & A & pT1aNOMO & $\mathrm{HN}$ & Contact 2D & 36 & 10 & 11 \\
\hline 7 & M & 38.6 & PCFCL & 12 & Oct 2019 & $P$ & cT1aNOMO & $\mathrm{HN}$ & Contact 3D & 30 & 10 & 11 \\
\hline
\end{tabular}

ID - identification number, PCLBCL LT - primary cutaneous diffuse large B-cell lymphomas, leg type, PCMZL - primary cutaneous marginal zone B-cell lymphoma, $P C L B C L O T$ - primary cutaneous diffuse large B-cell lymphomas, other type, $P C F C L$ - primary cutaneous follicle center lymphoma, $P T$ - primary treatment, $R$ - recurrence after previous surgery, $A$ - adjuvant after non-radical surgery, HN-head and neck, UB - upper back, LBB - lower back and buttock, LLAH - left lower arm and hand, PD - physical dose, Fx no. - number of fractions, OTT - overall treatment time, *lesions T2a treated as solitary tumors 
Table 3. Outcomes, toxicities, and biologically effective and equivalent doses of treatment

\begin{tabular}{|c|c|c|c|c|c|c|c|c|c|}
\hline $\begin{array}{l}\text { Patient } \\
\text { ID }\end{array}$ & $\begin{array}{l}\text { Lesion } \\
\text { ID }\end{array}$ & $\begin{array}{c}\text { FU } \\
\text { (months) }\end{array}$ & $\begin{array}{c}\text { BED } \\
(\alpha / \beta 10 \mathrm{~Gy})\end{array}$ & $\begin{array}{c}\mathrm{EQD}_{2} \\
(\alpha / \beta 10 \mathrm{~Gy})\end{array}$ & $\begin{array}{c}\text { Local } \\
\text { control }\end{array}$ & $\begin{array}{c}\text { Grade of early } \\
\text { toxicity }\end{array}$ & $\begin{array}{c}\text { BED } \\
(\alpha / \beta 3 \mathrm{~Gy})\end{array}$ & $\begin{array}{c}\mathrm{EQD}_{2} \\
(\alpha / \beta 3 \mathrm{~Gy})\end{array}$ & $\begin{array}{c}\text { Grade of late } \\
\text { toxicity }\end{array}$ \\
\hline 1 & 1 & 9.7 & 49 & 40.8 & Yes & 4 & 79.2 & 47.5 & 1 \\
\hline \multirow[t]{3}{*}{2} & 2 & 33.8 & 49 & 40.8 & Yes & 1 & 79.2 & 47.5 & 1 \\
\hline & 3 & 12.4 & 49 & 40.8 & Yes & 1 & 79.2 & 47.5 & 1 \\
\hline & 4 & 12.4 & 49 & 40.8 & Yes & 2 & 79.2 & 47.5 & 1 \\
\hline \multirow[t]{4}{*}{3} & 5 & 101.2 & 56 & 46.7 & Yes & 3 & 93.3 & 56 & 3 \\
\hline & 6 & 69.2 & 57.6 & 48 & Yes & 3 & 108 & 64.8 & 4 \\
\hline & 7 & 56.5 & 49 & 40.8 & Yes & 3 & 79.2 & 47.5 & 3 \\
\hline & 8 & 56.5 & 49 & 40.8 & Yes & 1 & 79.2 & 47.5 & 3 \\
\hline 4 & 9 & 24 & 50.4 & 42 & Yes & 1 & 84 & 50.4 & 1 \\
\hline 5 & 10 & 46.6 & 57.6 & 48 & Yes & 4 & 108 & 64.8 & 1 \\
\hline 6 & 11 & 63.7 & 49 & 40.8 & Yes & 2 & 79.2 & 47.5 & 2 \\
\hline 7 & 12 & 6 & 39 & 32.5 & Yes & 2 & 60 & 36 & 1 \\
\hline
\end{tabular}

$F U$-follow-up, BED - biologically effective dose, $E Q D_{2}$ - equivalent dose in 2 Gy per fraction

logical type, and include surgery (only very well limited PCMZLs and PCFCLs), systemic treatment (as first-line treatment in case of PCLBCLs), and radiotherapy (firstline treatment in PCMZLs and PCFCLs, combined with systemic treatment for PCLBCs, or solitary treatment as an alternative for combined treatment) [5]. Recommended forms of radiotherapy consist of electrons (6 to $9 \mathrm{MeV}$ ) with boluses (to avoid skin-sparing) or low energy X-rays (approximately $100 \mathrm{kV}$ ). In cases of tumors with deep infiltration or located at curved surfaces, it is recommended to use high-energy photon radiation. Recommended EBRT doses range from 24 to $40 \mathrm{~Gy}$ in conventional fractionation. The dose should be specified to the primary tumor with a safe margin of $1-2 \mathrm{~cm}$ (to the sides and depth) $[4,5,6,7]$. A cumulative summary of studies concerning EBRT shows excellent efficacy resulting in a 99\% CR rate for PCMZLs and PCFCLs, and an 88\% CR rate for PCLBCLs [4].

In comparison to the above-mentioned EBRT recommendations, the presented 2 Gy normalized doses in this report, in most of the cases, were slightly higher than $40 \mathrm{~Gy}$ (median, $40.8 \mathrm{~Gy}$ ). However, due to unique aspect of HDR-BT, i.e. steep dose fall-off with squared distance from the radioactive source, dose values on the skin surface and in the tumor were substantially higher, which could potentially influence better therapeutic result. On the other hand, the steep dose fall-off might result in a higher number of marginal recurrences. In the presented group of patients, depending on the planning method, safety margins added to clinically visible tumors were smaller than these recommended for EBRT, and varied from 0 (3D planning) to $5 \mathrm{~mm}$ (2D planning), so that the areas covered by $100 \%$ isodose ranged from 2.25 to $41.5 \mathrm{~cm}^{2}$ (mean, $19.9 \mathrm{~cm}^{2}$; median, $20 \mathrm{~cm}^{2}$ ). It means that the median $\mathrm{EQD}_{2}$ at a distance of $1 \mathrm{~cm}$ from the treated lesion was in the range between 17.7-28.6 Gy (the margin was covered by isodoses of $50-75 \%$ of PD), which was still high enough in the presented group to prevent local recurrences in the irradiated sites.

Interestingly, quite a high percentage of occurred late effects higher than G2 (33\% total) was observed. It is higher than reported $8.6 \%$ for EBRT results [17]. In our institution, HDR-BT has been used for many years in the treatment of various skin neoplasms, most often basal cell carcinomas, squamous cell carcinomas, and distant skin metastases of different origins. Fractionation regimens used in these cases were more aggressive than for the treatment of CBCLs, and despite that, late effects graded higher than G2 were merely 3.4-11\% [18,19].

All high-grade late effects occurred in patient no. 3 only. One case of small ulceration (G4) developed over five years after the completion of interstitial treatment of lesion no. 6 (Table 2). The ulceration occurrence may be partially explained by the high value of BED, calculated for late reactions in the delivered regimen of radiation with short OTT. Additionally, the lesion was located in an old scar after Lyme disease, in a tissue, where the initial regeneration capacity was limited. The patient also indicated to undertake physical activity in a gym, and the exercises, i.e. lying on his back (on a bench) with a load, could be considered as an additional possible damaging factor. Also, other late reactions in the form of massive telangiectasia occurred in areas treated with more extended regimens and lower doses that did not cause such substantial complications in other patients. The same pattern as for lesion number 6 , but for a contact treatment was used for another patient to treat lesion number 10, where a delayed reaction of only G1 after almost four years was observed. In our opinion, this information suggests that the occurrence of much worst reactions in patient no. 3 may have been caused by an increased individual sensitivity to ionizing radiation, which is frequently disregarded in clinical practice but has been described 
in the literature from the very beginning of radiotherapy $[20,21]$.

\section{Conclusions}

To our knowledge, this work is the first to demonstrate a series of cases of CBCLs treated with HDR-BT. This method allows for achieving high local control, with relatively low late toxicity in the form of skin discoloration in most of the patients.

\section{Disclosure}

The authors report no conflict of interest.

\section{References}

1. Groves FD, Linet MS, Travis LB, Devesa SS. Cancer Surveillance Series: Non-Hodgkin's lymphoma incidence by histologic subtype in the United States from 1978 through 1995. J Natl Cancer Inst 2000; 92: 1240-1251.

2. Willemze R, Jaffe ES, Burg G et al. WHO-EORTC classification for cutaneous lymphomas. Blood 2005; 105: 3768-3785.

3. Willemze R, Cerroni L, Kempf W et al. The 2018 update of the WHO-EORTC classification for primary cutaneous lymphomas. Blood 2019; 133: 1703-1714.

4. Specht L, Dabaja B, Illidge $\mathrm{T}$ et al. modern radiation therapy for primary cutaneous lymphomas: field and dose guidelines from the International Lymphoma Radiation Oncology Group. Int J Radiat Oncol Biol Phys 2015; 92: 32-39.

5. Nancy SJ, Noordijk EM, Kim YH et al. European Organization for Research and Treatment of Cancer and International Society for Cutaneous Lymphoma consensus recommendations for the management of cutaneous B-cell lymphomas. Blood 2008; 112: 1600-1609.

6. NCCN. National Comprehensive Cancer Network. Primary cutaneous B-cell lymphomas 1.2020. 2020.

7. NCCN. National Comprehensive Cancer Network. Diffuse large B-cell lymphoma 1.2020. 2020.

8. Skowronek J. Current status of brachytherapy in cancer treatment - a short overview. I Contemp Brachytherapy 2017; 9: 581-589.

9. Delishaj D, Rembielak A, Manfredi B et al. Non-melanoma skin cancer treated with high-dose-rate brachytherapy: a review of the literature. J Contemp Brachytherapy 2016; 8: 533-540.

10. Guinot JL, Rembielak A, Perez-Calatayud J et al. GEC-ESTRO ACROP recommendations in skin brachytherapy. Radiother Oncol 2018; 126: 377-385.

11. DeSimone JA, Guenova E, Carter JB et al. Low-dose highdose-rate brachytherapy in the treatment of facial lesions of cutaneous T-cell lymphoma. J Am Acad Dermatol 2013; 69 61-65.

12. Goddard AL, Vleugels RA, LeBoeuf NR et al. Palliative therapy for recalcitrant cutaneous T-cell lymphoma of the hands and feet with low-dose, high dose-rate brachytherapy. JAMA Dermatol 2015; 151: 1354-1357.

13. Kim YH, Willemze R, Pimpinelli N et al. TNM classification system for primary cutaneous lymphomas other than mycosis fungoides and Sézary syndrome: a proposal of the International Society for Cutaneous Lymphomas (ISCL) and the Cutaneous Lymphoma Task Force of the European Organization of Research and Treatment of Cancer (EORTC). Blood 2007; 110: 479-484.

14. Wilder RB, Tucker SL, Ha CS et al. Dose-response analysis for radiotherapy delivered to patients with intermediate-grade and large-cell immunoblastic lymphomas that have completely responded to CHOP-based induction chemotherapy. Int J Radiat Oncol Biol Phys 2001; 49: 17-22.

15. Fowler JF. Practical time-dose evaluations, or how to stop worrying and learn to love linear quadratics. In: Levitt $\mathrm{SH}$, Purdy JA, Perez CA, Poortmans P (eds.). Technical Basis of Radiation Therapy. Medical Radiology. Springer, Berlin, Heidelberg 2011.

16. Cox JD, Stetz J, Pajak TF et al. Toxicity criteria of the Radiation Therapy Oncology Group (RTOG) and the European Organization for Research and Treatment of Cancer (EORTC). Int J Radiat Oncol Biol Phys 1995; 31: 1341-1346.

17. Eich HT, Eich D, Micke O et al. Long-term efficacy, curative potential, and prognostic factors of radiotherapy in primary cutaneous B-cell lymphoma. Int J Radiat Oncol Biol Phys 2003; 55: 899-906.

18. Skowronek J, Chicheł A, Piotrowski T. HDR brachytherapy of skin cancer - the Wielkopolski Cancer Centre's experience. Contemp Oncol 2005; 9: 347-354.

19. Chyrek AJ, Burchardt WM, Adamska M et al. How to efficiently treat skin basal cell carcinoma without using computed tomography? 2D HDR brachytherapy as the answer for emerging countries. Brachytherapy 2019; 18: S104-S105.

20. Foray N, Colin C, Bourguignon M. 100 Years of individual radiosensitivity: how we have forgotten the evidence. Radiology 2012; 264: 627-631.

21. Tucker SL, Turesson I, Thames HD et al. Evidence for individual differences in the radiosensitivity of human skin. Eur J Cancer 1992; 28: 1783-1791. 